
About IJMA [last updated July, $\left.1^{\text {st }}, 2021\right]$

$\checkmark$ International Journal of Medical Arts is the Official Journal of the Damietta Faculty of Medicine, AlAzhar University, Egypt

$\checkmark$ It is an International, Open Access, Double-blind, Peer-reviewed Journal

$\checkmark$ Published four times a year

$\checkmark$ The First Issue was published in July 2019

$\checkmark$ Published under the following license: Creative Commons Attribution-ShareAlike 4.0 International Public License (CC BY-SA 4.0). It had updated from the Creative Commons license [CC BY] in volume 2, Issue 4, October 2020 About IJMA

$\checkmark$ The Egyptian Knowledge Bank hosts the web site of IJMA

$\checkmark$ The Egyptian Knowledge Bank supports IJMA

$\checkmark$ IJMA follows the regulations of the International Committee of Medical Journal Editors

$\checkmark$ IJMA is indexed in the "Directory of Open Access Journals" [15 January 2021].

$\checkmark$ IJMA is indexed in JGate [29-6-2021]

$\checkmark$ IJMA is a member of the International Society of Managing and Technical Editors

$\checkmark$ Listed in "Index Copernicus", "Publons", "Academic resource index [ResearchBib]", "Electronics journal library", "Eurasian Scientific Journal Index", and "Citefactor"

$\checkmark$ IJMA introduced to the search engine [BASE] through DOAJ
Click image to reach the page

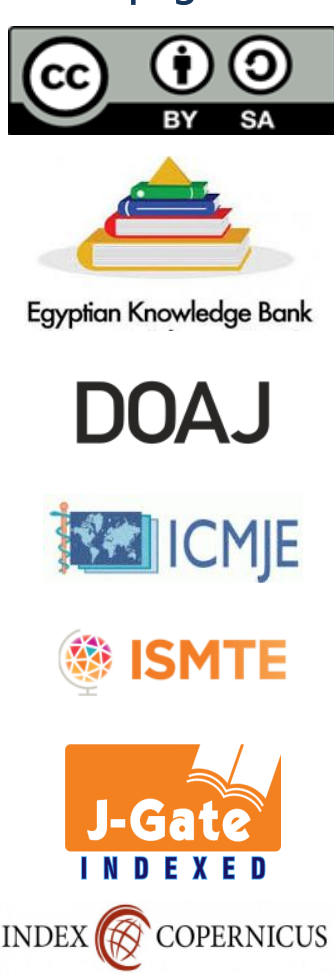

publons

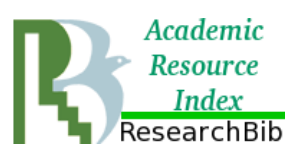

\section{EZ3 \\ .}

ESJII

CiteFactor

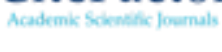

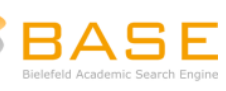




Available online at Journal Website
https://ijma.journals.ekb.eg/
Main subject [Neurosurgery] ${ }^{*}$

Original Article

\title{
Dorsolumbar Spinal Infection, Surgery versus Conservative Treatment
}

\author{
Ahmad Mofreh Elmezain
}

Tanta Health Insurance Hospital, Ministry of Health, Egypt

Email: ahmad.mofreh@gmail.com

Submission date: March 04, 2021; Revision date: April 29, 2021; Acceptance date: June 16, 2021

DOI: 10.21608/IJMA.2021.66161.1275

\section{ABSTRACT}

Background: The spinal infection is defined as infection accompanied by the destruction of the vertebral bodies, starting at the endplate with secondary involvement of the intervertebral disks. Patients with spinal infection experience back pain with or without fever.

Aim of the Work: The aim of the current study was to compare the results for both surgical interference and conservative methods in managing dorsolumbar spinal infections.

Patients and Methods: This was a prospective study that included 30 patients with dorsolumbar spinal infection. They were admitted and managed at the Neurosurgery Department, Al-Azhar University hospitals and Health Insurance hospitals through the period of 2015 to 2020 .

Result: The disease was more common in males. Patient age ranged from 29 to 65 years. Diabetes mellitus was the most common reported comorbidity. The most affected region was the thoracic region followed by the lumbar region. Diagnosis was established bacteriologically for $32 \%$. The average erythrocyte sedimentation rate [ESR] in the first hour was $84.5 \mathrm{~mm} / \mathrm{hr}$, elevated in the second hour to $94 \mathrm{~mm} / \mathrm{hr}$. C-reactive protein [CRP] level was greater than $10 \mathrm{mg} / \mathrm{L}$ in all cases with an average of $55.8 \mathrm{mg} / \mathrm{L}$. All patients received more than 4 weeks of antibiotic therapy. The outcome was excellent to good outcome among $60 \%$ and $73.3 \%$. Fair outcome was $13.3 \%$ and $20 \%$, poor outcome, was $20 \%$ and $6.7 \%$, and patients died was $6.7 \%$ and $0 \%$, in conservative and surgical groups, respectively. Relapse developed in $10 \%$ of patients.

Conclusion: ESR and CRP were very important in both diagnosis and follow-up [with CRP superior to ESR]. Surgery is superior than conservative treatment.

Keywords: Spinal Infection; Vertebral Osteomyelitis; Disk Space Infection; Spondylodiscitis; Epidural Abscess.

This is an open-access article registered under the Creative Commons, ShareAlike 4.0 International license [CC BY-SA 4.0] [https://creativecommons.org/licenses/by-sa/4.0/legalcode.

Citation: Behiery AT, Sayouh AS, Salem NA. Dorsolumbar Spinal Infection, Surgery versus Conservative Treatment. IJMA 2020; 3[3]: JulySeptember: 1611-1617. [DOI: 10.21608/JMA.2021.66161.1275].

* Main subject and any subcategories have been classified according to the research topic. 


\section{INTRODUCTION}

The spinal infection [SI] is defined as infection accompanied by the destruction of the vertebral bodies, starting at the endplate, with secondary involvement of the intervertebral disks. It can involve any anatomical area around the spine, including the disc, vertebral body, muscular involvement [psoas abscess or paraspinal abscess] paravertebral soft tissues and the epidural space [epidural abscess] [1]. The spinal infection remains primarily a monomicrobial bacterial infection, and polymicrobial infections are uncommon [2]. It may occur by Bacteria [Tuberculosis, staphylococcus aureus, methicillin-resistant staphylococcus aureus [MRSA], Gram-negative bacilli [Escherichia coli, Proteus and Pseudomonas aeruginosa], Brucellosis, Staphylococcus epidermidis, etc.], Fungi [candida species, aspergillus and cryptococcus neoformans], and parasites [Echinococcus granulosus; Hydatid cyst] [3]. Organisms arrive in the spine either through hematogenous [arterial or venous] or non-hematogenous routes [interventional procedures, trauma, contiguous infection and direct inoculation] [4].

Diagnosis of the spinal infection is based on clinical, laboratory and radiological features [5]. The patient may suffer from back pain, fever, neurological deficit, bowel and bladder dysfunction, weight loss, and wound drainage in case of SSI [6]. Laboratory findings include Elevated erythrocyte sedimentation rate $[E S R]$ and $C$-reactive protein [CRP], leukocytosis, blood cultures, tuberculin skin test, serology for cases suspected of having Brucella, biopsy and culture and histopathology ${ }^{[7]}$.

Radiological investigations include plain radiographs ${ }^{[8]}$, and magnetic resonance imaging [MRI]. MRI with Gadolinium enhancement is optimum for diagnosing spondylodiscitis, this is due to its high sensitivity [96\%], specificity [97\%] and greater capacity to provide detailed anatomical information about surrounding soft tissues, epidural space and assessment of any compression of neural elements ${ }^{[1]}$.

Computed tomography [CT] is the best for evaluation of bony changes ${ }^{[5]}$. The treatment of spinal infection is either conservative or surgical. The conservative management consists of antibiotics, analgesics, external im-mobilization, and physical therapy. It can be considered if the clinical symptoms and the destruction are relatively mild or the risk of operation appears to be too great ${ }^{[5]}$. The objectives of the surgical intervention are to remove the septic focus, detect the pathogen and to stabilize the infected section of the spinal column. This provides a more reliable and more rapid treatment of the consequences of the infection, and allows rapid postoperative mobilization ${ }^{[9]}$.
AIM OF THE STUDY

The aim of the study was to compare between the results of surgical and conservative treatment methods in the management of dorsolumbar spinal infections.

\section{PATIENTS AND METHODS}

After approval of medical ethics committee, thirty patients with dorsolumbar spinal infection were included in our prospective study, they managed at the neuro-surgery department of Al-Azhar University hospitals and Health Insurance hospitals through the period of 2015 to 2020. Patients who were included in the study fulfilled the following characters: Confirmed dorsal or lumbar spinal infection, no neurological deficit, and spinally stable. On the other side, patients were excluded if there was any neurological deficit, or spinal instability.

MRI was done for all cases. Plain X-ray and CT of the dorsal or lumbar spines were performed for selected cases. Complete blood count [CBC], Erythrocyte sedimentation rate $[E S R], C$-reactive protein [CRP] and blood cultures were performed for all cases. Blood sugar [fasting, two hours post-prandial and glycated hemo-globin; $\mathrm{HbA} 1 \mathrm{c}$ ], liver and renal function tests [ALT, AST, albumin, blood urea nitrogen, creatinine], pro-thrombin time and activity, ECG and echocardiography for selected patients. A written informed consent was obtained from all subjects. There were any additional considerations. Patients were divided randomly into two equal groups, as follow:

A. Group A [Conservative treatment]: The general principles for conservative management are

1. Antibiotics: Antibiotic therapy was initiated after a definitive etiological diagnosis was done either by blood cultures or bone-biopsy samples in most cases. In case of sepsis or the impossibility of an etiologic diagnosis, empirical antibiotic therapy was started [Linezolid $600 \mathrm{mg}$ tablet BID for 10-14 days [maximum for 28 days] and Levofloxacin $500 \mathrm{mg}$ tablet $\mathrm{OD}$ or BID for 14 days].

2. Analgesics: Acetaminophen, and nonsteroidal antiinflammatory drugs.

3. Immobilization: The immobilization [in the form of hard lumbosacral support or hard dorso-lumbar support] of the affected level for all patients.

4. Bed rest for the initial 2-4 weeks followed by ambulation with appropriate brace or corset.

5. Physical therapy: For function recovers therapy [strength, coordination stability, mobility].

B. Group B [Surgical interference]: Mainly, posterior 
approach was used to remove the septic focus, detect the pathogen and to stabilize the infected section of the spinal column. Antibiotics, analgesics, immobilization, bed rest and physical therapy are also considered.

Assessment of the results: The first outpatient examination started 2 weeks after surgery for stitch removal [in case of surgical intervention], the second visit was 3 months later for assessment of the clinical, radiological and laboratory condition of the patient.

\section{RESULTS}

Out of the 30 patients in the study, 17 patients were males and 13 patients were females [Male: Female ratio was 1.3:1]. Age ranges from 29 to 65 years [average: 49 and median 51 ]. Cases living in urban and rural areas were $37 \%$ and $63 \%$, respectively. The infection affected the dorsal level more than lumbar level $[57 \%$ versus $43 \%$, respectively]. Time between the clinical onset and diagnosis of SI ranged from less than one month to 9 months [average: 5.4 months and median: 6 months].

Erythrocyte sedimentation rate [ESR] in the first hour ranged from $26 \mathrm{~mm} / \mathrm{hr}$ to $120 \mathrm{~mm} / \mathrm{hr}$ [average: $84.5 \mathrm{~mm} / \mathrm{hr}$ and median: $93 \mathrm{~mm} / \mathrm{hr}$ ]. In the second hour, it ranged from $45 \mathrm{~mm} / \mathrm{hr}$ to $132 \mathrm{~mm} / \mathrm{hr}$ [average: $94 \mathrm{~mm} / \mathrm{hr}$ and median: $97.5 \mathrm{~mm} / \mathrm{hr}$ ]. C-reactive protein [CRP] ranged from $17 \mathrm{mg} / \mathrm{L}$ to $104 \mathrm{mg} / \mathrm{L}$ [average: $55.8 \mathrm{mg} / \mathrm{L}$ and median: $56 \mathrm{mg} / \mathrm{L}$ ]. Total leukocytic count [TLC] ranged from $5.700 \times 10^{\wedge} 3$ to 16.700 $\times 10^{\wedge} 3 \mathrm{wbc} / \mathrm{mm}^{3}$. [Average: $12.037 \times 10^{\wedge} 3 \mathrm{wbc} / \mathrm{mm}^{3}$ and median: $12.15 \times 10^{\wedge} 3 \mathrm{wbc} / \mathrm{mm}^{3}$ ]. The causative organism was identified by either blood cultures or biopsy, in $32 \%$ of cases [staphylococcus aureus: 16\%; TB: 8\%; Escherichia Coli: 4\%; Brucella Melitensis: 4\%], and was not identified in $68 \%$. Forty-three point three per cent of cases were hypertensive, $33.3 \%$ were diabetic, $6.6 \%$ were cardiac, $13.3 \%$ had a urinary tract infection [UTI] in the past year, $10 \%$ had a body mass index [BMl] $>/=25 \mathrm{~kg} / \mathrm{m}^{2}$ [mostly, surgical site infection] and $26.7 \%$ had no comorbidities.

\section{The outcome:}

The outcome for conservative treatment and surgical intervention using Macnab criteria [regarding presence and type of pain, restriction of mobility, and ability to return to normal work]: Excellent to good outcome was $60 \%$ and $73.3 \%$, respectively, Fair outcome was $13.3 \%$ and $20 \%$, poor outcome, progressed neurological compromise $20 \%$ and $6.7 \%$, and patients died was $6.7 \%$ and $0 \%$. Relapse had occurred in three patients; two patients who had undergone conservative treatment, and one had surgical intervention. Intervals between the clear resolution of symptoms and relapse ranged from 4 months to 11 months [average $=7.5$ months]. The mortality rate was $3.3 \%$ [1 of the 30 cases]. The cause of death was cardiac arrest due to very bad general condition, highly elevated liver and kidney enzymes, and bad blood gases.

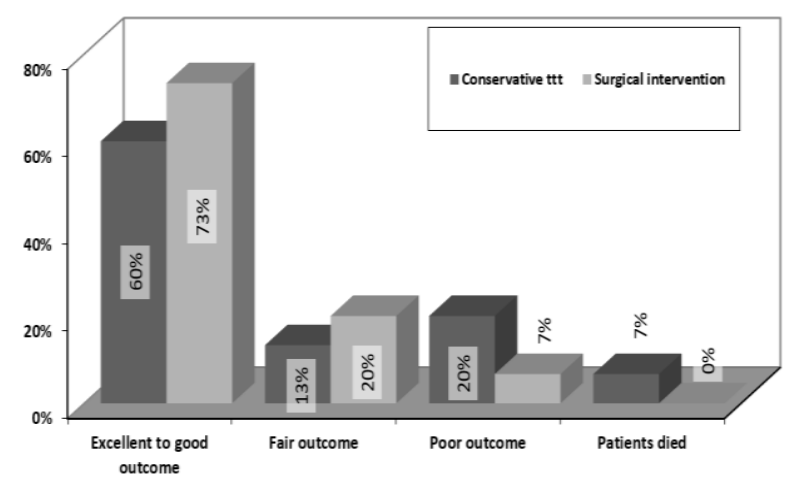

Figure [1] Histogram showing the outcome for both conservative treatment and surgical intervention groups.

Table [1]: The average follow-up TLC, ESR and CRP at 1, 2, 4, and 8 weeks

\begin{tabular}{|l|c|c|c|c|c|}
\hline & Day 0 & Week 1 & Week 2 & Week 4 & Week 8 \\
\hline TLC WBCs/mm3 & 12.037 & 9.823 & 8.783 & 7.314 & 6.504 \\
\hline ESR [mm/hr] & 84.5 & 75.6 & 65.6 & 50.9 & 29.2 \\
\hline CRP [mg/L] & 55.8 & 31.4 & 21.1 & 17.7 & 4.8 \\
\hline
\end{tabular}

In the subsequent section, we present some cases. The first was fifty-seven years old man with a history of diabetes mellitus presented with severe low back pain started one month after lumbar spine surgery [L3-4 and L4-5 posterior decompression and fixation] and severe surgical site infection. The patient was neurologically intact. MRI LSS shows a huge subfascial collection of pus at the level of the $3^{\text {rd }} 4^{4^{\text {th }}}$, and $5^{\text {th }}$ lumbar vertebrae covering the transpedicular screws' caps. The patient underwent conservative measures in the form of antibiotics, analgesics, lumbar brace and immobilization for 4 weeks, care of the surgical site infection [repeated dressing], and control of blood sugar levels. There was a dramatic relief of back pain with these conservative measures. The second was, forty-two-year-old female patient with history of diabetes mellitus presented with dorsal pain and fistula discharging pus eight years ago, the patient had a history of spinal surgery [D11-L2 fixation] at 2008 , the fistula was treated surgically several times by general surgery specialist. The patient was neurologically intact with no spinal instability. Plain radiography and CT showed 4 pedicular screws and 2 rods used to fix D11 with L2 with fused D12 with L1 vertebrae. MRI of dorso-lumbar spine showed posterior epidural and subcutaneous collection at the level of D11, 12, L1, 2 vertebrae. Dorsal vertical mid-line skin incision, muscle separation, laminectomy of D11 and hemi-laminectomy of D12, evacuation of the collection, hemostasis was performed, vacuum drain was applied, closure in layer. The specimen was collected and sent for bacteriological culture and histopathological examination. No fixation was done. Post- 
operatively, the patient improved with regard to the dorsal pain [Figures 2 and 3]. After 9 months: MRI of the dorsolumbar spines showed complete resorption of the pus collection [Figure 4].

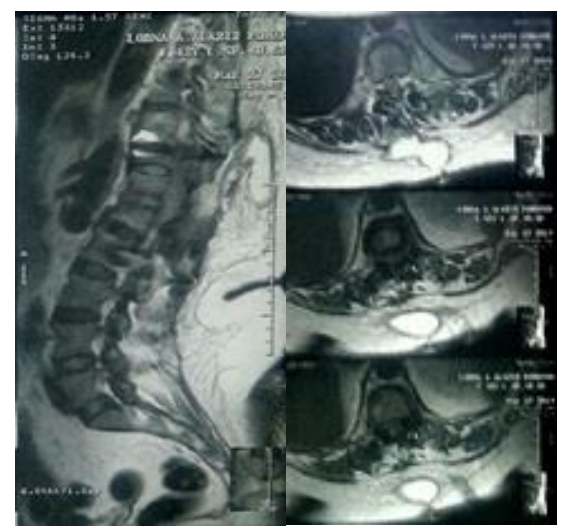

Figure [2] MRI dorso-lumbar spines [sagittal and axial views] [T1, T2, and T1 with contrast] shows posterior collection of pus at the level of dorsal vertebral 11 and partially 12 with fistula connecting it with the skin.

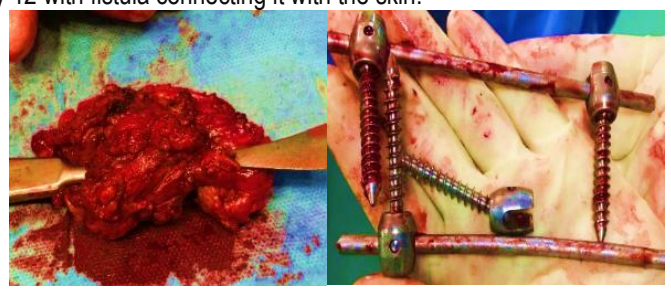

Figure [3] a] Scar and perifistula tissue after removal, with the osteotome passed in the fistula track. b] Old pedicular screw fixation system after removal as a single unit due to osteolytic effect of pus on vertebral bone.

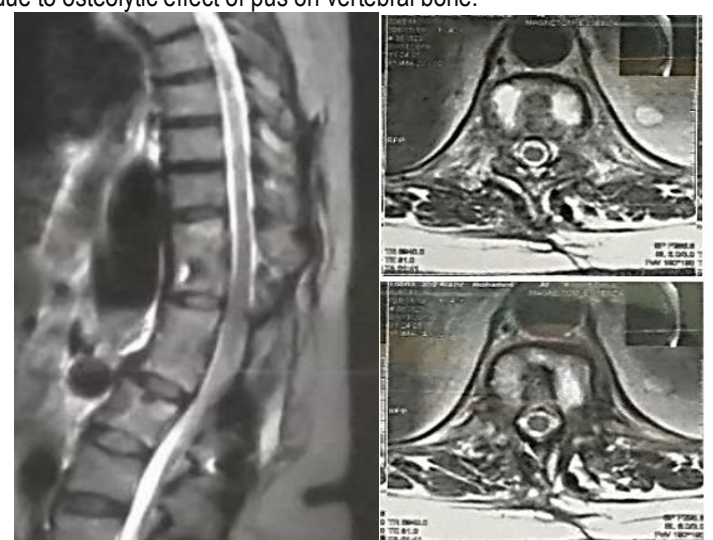

Figure [4] T1WI sagittal and axial MRI of the dorsolumbar spines shows complete resorption of the pus collection.

\section{DISCUSSION}

The disease is more common in males. Males account $56.7 \%$ [17 patients], while females account $43.3 \%$ [13 patients] [male: female ratio $=1.3: 1$ ] which is correlated with studies by Wille et al. and Moon et al. [1.4:1 and 1.5:1, respectively] [10, 11]. Patient age range from 29 to 65 years [median: 51 years; average: 48.97]. Wille et al. and McHenry et al. found that the median age was, nearly, greater than it in our study [57,60 years, respectively] ${ }^{[10,12]}$. Fifty-three per cent of patients in our study [16 of 30 patients] were above 50 years. There was a predominance of distribution of cases in rural over urban areas $[73.3 \%$ vs $26.7 \%$, respectively]. Grammatico et al. found that the occurrence in rural and urban areas was 50:50\% [13]. The difference in values may be due to the big difference between the nature of rural areas in Egypt vs France regarding types of work, instrument and facility, dealing with milk and milk products, level of education and quality of medical service.

No seasonal variation was noted. Grammatico et al. found similar result ${ }^{[13]}$. The most frequent comorbidity was diabetes mellitus [DM], it has been reported in 33.3\% [10 patients], it has been reported as a comorbidity in $10.8 \%$ and $25 \%$ of patients in studies conducted by Wille et al. and Yoon et al. ${ }^{[10,14]}$. Diabetes is a major risk factor for postoperative infection. White cell function is affected with blood glucose levels higher than $200 \mathrm{mg} / \mathrm{dL}^{[15]}$.

Thirteen point thirty-three per cent [4 patients] had urinary tract infection [UTI] in the last year before diagnosis. Carragee found that TUI was the most frequent source of spinal infection as it was confirmed in $27 \%$ of patients and suspected in $18.9 \%$ of patients [16]. The great difference between the two studies may be due to improper medical system recording [regarding our patient], undiagnosed UTI, and resorting of Egyptian patients to automedication without medical prescription and accurate diagnosis.

Three patients [10\%; all have surgical site infection] had a BMI [body mass index] $>1=25 \mathrm{~kg} / \mathrm{m}^{2}$. Wille et al. found the prevalence of obesity among patients with spinal infection as $56.6 \%$ [10]. The most affected region was the thoracic level, constituting for $56.6 \%$ of cases [17 of the 30 cases], followed by the lumbar region. This result is correlating with the study by Moon et al. [11]; $63.3 \%$ of cases. Gentile et al. found that the lumbar region was the most frequent site ${ }^{[17]}$. There are just 10\% [3 patients] that were diagnosed in the first month of the beginning of manifestations, $16.7 \%$ [5 patients] were diagnosed in the $2^{\text {nd }}$ and $3^{\text {rd }}$ months, $74 \%$ [22 patients] were diagnosed in the $4^{\text {th- }} 9^{\text {th }}$ months [average: 5.4 months and a median: 6 months]. However, Carragee reported that the diagnosis was confirmed for $69 \%$ of patients within the first month of illness ${ }^{[16]}$.

The most frequent presenting clinical manifestation was back pain [in $100 \%$ of patients]. Farajzadeh et al. [6] and Kwon ${ }^{[18]}$ reported back pain as the most common initial symptom in $100 \%$ and $80 \%$, respectively. Fever was present in $50 \%$. In studies by Farajzadeh et al. ${ }^{[6]}$, Kwon ${ }^{[18]}$ and Yoon et al. ${ }^{[14]}$, it was present in $35 \%, 44 \%$, and $60 \%$ of cases, respectively. The duration of back pain before established diagnosis ranged from 28 days to 8.5 months [average: 5.4 months and median: 6 months]. Kwon [18] 
mentioned that the duration may be as long as several months.

The relative frequency of accompanying abscesses [epidural or paravertebral] in the dorsal and lumbar regions was $16.7 \%$ and $10 \%$, respectively, which are nearly correlating with results by McHenry et al. [22\% and $12 \%$ for dorsal and lumbar regions, respectively] ${ }^{[12] .}$

The average ESR value in the first hour were $84.5 \mathrm{~mm} / \mathrm{hr}$ [the minimum were 20 and the maximum were 120]. Priest and Peacock reported an average peak ESR in the first hour of $101 \mathrm{~mm} / \mathrm{h}$ [range 13 to more than $140 \mathrm{~mm} / \mathrm{h}$ ] ${ }^{[19]}$. Twentysix patients of 30 patients [87\%] had ESR in the first hour more than $50 \mathrm{~mm} / \mathrm{h}$, which is correlated with the result by Gouliouris et al. [91\%] ${ }^{[5]}$. In the second hour, the average ESR value was $94 \mathrm{~mm} / \mathrm{hr}$ [the minimum was 50 and the maximum was 136], no sufficient data about ESR in the second hour was present in other studies.

CRP level was increased in all cases, it ranged from $17 \mathrm{mg} / \mathrm{L}$ to $104 \mathrm{mg} / \mathrm{L}$ [average: $55.8 \mathrm{mg} / \mathrm{L}$ and a median: $45 \mathrm{mg} / \mathrm{L} ;$ no extreme values]. This result is correlated with the result by Chelsom and Solberg [20]. They found that all patients had a value greater than $10 \mathrm{mg} / \mathrm{L}$.

Total leukocytic count was high [more than 11.000 wbc/cc 3 in $80 \%$ and not found to be helpful in diagnosis. Stoffel et al. [21] and Zimmerli et al. [22] reported that increased leukocyte counts were found in $37 \%$ and $74 \%$, respectively. So, they stated that increased leukocyte count has a low sensitivity for the diagnosis of osteomyelitis.

By blood cultures, the causative organisms were identified in only $26.7 \%$ [ 8 of 30 patients], while in $73.3 \%$ [ 22 of 30 patients], no organism could be identified. The fraction of positive blood cultures in studies by Marschall et al. [23] and Yoon et al. ${ }^{[14]}$ were $60 \%$ and $30 \%$.

In cases underwent surgery, $46.6 \%$ of Open-sky biopsy were positive in detecting the causative organism [7 of 15 patients]. The fraction of positive biopsy cultures in studies by Marschall et al., Yoon et al. and Bettini et al. was 38\%, $100 \%$, and $86 \%$ [14,23,24]. Yang et al. [25] showed that percutaneous endoscopic discectomy had a yield of positive cultures as $90 \%$. In patients confirmed bacteriologically, the responsible pathogens were Staphylococcus Aureus [50\%], tuberculosis [25\%], Escherichia coli [12.5\%] and Brucella melitensis [12.5\%], which is partially corresponding to results reported by Wille et al. They reported that Staphylococcus aureus, Escherichia coli and polymicrobial infections were identified in $44 \%, 18 \%$, and $13 \%$, of cases established bacteriologically. In addition, no cases were recorded in their study regarding TB ${ }^{10]}$.
All patients received more than 4 weeks of antibiotic therapy. Oral antimicrobial medication was administered most frequently as a relay to parenteral therapy, but it constituted definitive therapy in some patients. There are no data from controlled trials on the optimal duration of antimicrobial therapy. Talia et al. ${ }^{[26]}$ and Livorsi et al. [27] recommended treatment for 3-12 months for pyogenic patients and for 12 months in patients with tuberculous osteomyelitis along with institutional tuberculosis protocol. The recommendations by Berbari et al. [7] are that antimicrobial therapy ranges from 4 to 6 weeks.

We followed up the patients using the Visual Analog Scale [VAS] [pain scale]. We found a significant reduction of pain in one month after treatment either conservative or surgical from an average 8.1 and 8.4 to 4.93 and 4.2 respectively. At 6 months, there was a further drop to an average VAS 2.3 and 1.9, respectively. At 12 months, an average VAS was 2 and 1.3, respectively. Talia et al. found that there was a significant reduction of pain from an average preoperative VAS of 8.56 to post-operative VAS 3.75 at 3 months. There was a further but non-significant drop to VAS 2.86 at 6 months and VAS 1.5 at 12 months ${ }^{[26] .}$

The average follow-up ESR in the 1 st hour on day 0 , and $1,2,4$, and 8 weeks were $84.5,75.7,65.6,50.9$, and $29.2 \mathrm{~mm} / \mathrm{hr}$, respectively, which is correlated with a study by Yoon et al. They found the average follow-up ESR in the first hour on day 0 , and 1,2, 4, and 8 weeks were $67,72,65,52$, and $50 \mathrm{~mm} / \mathrm{hr}^{[14]}$. The rise in CRP value at 1 week, from 67 to $72 \mathrm{~mm} / \mathrm{hr}$ in their study is not really understood. Also, they were found that [ESR] over $55 \mathrm{~mm} / \mathrm{hr}$ and CRP over $2.75 \mathrm{mg} / \mathrm{dl}$ at fourth week after antibiotic administration predict treatment failure ${ }^{[14]}$.

The average follow-up CRP on day 0 , and 1, 2, 4, and 8 weeks was $55.8,31.4,21.1,17.7$, and $4.8 \mathrm{mg} / \mathrm{L}$, respectively. The average follow-up of CRP in the study by Yoon et al. They found the average follow-up ESR in the $1^{\text {st }}$ hour on day 0 , and $1,2,4$, and 8 weeks were $13,4.8,3.5$, 2.5 , and $2.5 \mathrm{mg} / \mathrm{L}$ [14]. Although the meticulous work, from us, in both recording and analyzing the laboratory data, the cause of the great variation in CRP values is not fully understood.

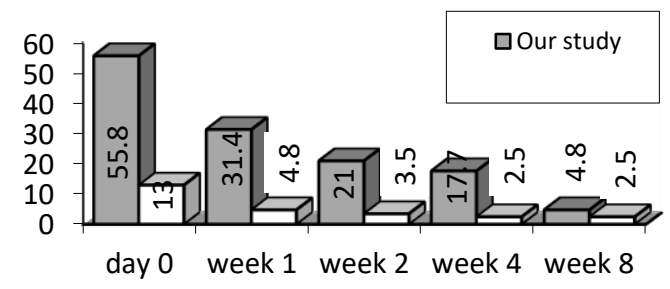

Figure [5]. Histogram showing the average follow-up CRP on day 0, and 1, 2, 4, and 8 weeks for our study and the study by Yoon et al. ${ }^{[14]}$. 
Duarte and Vaccaro stated that a weekly reduction of $50 \%$ in CRP suggests a favorable evolution, and accepted criteria for discontinuing the antimicrobial treatment include improvement or resolution of the symptoms and normalization of ESR or CRP [4]. Hong et al. in his retrospective study on 10 patients with spinal infection found that the $\mathrm{C}$-reactive protein level of most patients returned to the normal range within 10 weeks ${ }^{[28]}$.

We found MRI useful only in following up patients with pyogenic infection and collections since we found poor correlation between clinical healing and improvement on MRI. Euba et al. concluded that repeat MRI is unnecessary if clinical and laboratory outcomes are satisfactory [29].

Outcome results of conservative treatment were correlated with results by Rezai et al. They reported that $75 \%$ of patients who were initially underwent conservative treatment had successful medial therapy, and $25 \%$ had failed treatment $\left[63.3 \%\right.$ and $26.7 \%$ in our study] ${ }^{[30]}$. Bettini et al. found that the conservative management of infection with antibiotic therapy and spinal bracing was very successful [24]

Results of surgical outcome in the current study were similar to those reached by Yang et al. in his study on patients undergone surgical interference [percutaneous endoscopic debridement with dilute betadine solution irrigation; PEDI], they found that $84.4 \%$ reported satisfactory relief of their back pain one week after PEDI, 12.5\% had fair outcomes, and $3 \%$ had a poor outcome $[73.3 \%, 20 \%, 6.6 \%$ in our study] ${ }^{[31]}$.

Relapse developed in 3 patients [10\%]: 2 patients who had undergone conservative management and 1 patient who had undergone surgical intervention [evacuation of abscess, debridement of infected bone and fistulectomy]. The recurrence was due to incomplete debridement, and no biopsy was taken for culture and sensitivity. So, no suitable antibiotic was taken. The 3 patients then underwent surgical intervention. In studies by Pigrau et al. and McHenry et al.

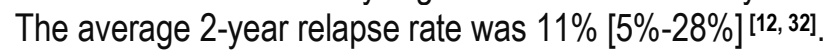

Intervals between the clear cure [relief of pain, normalization of ESR and CRP and stoppage of antimicrobial] and the development of relapse in the 3 patients were 4, 9, and 11 months [average $=8$ months]. Seung et al. ${ }^{[2]}$ found that $75 \%$ of relapse occurred within the first year, the timing ranging from less than 1 month to as long as 12 year's post-treatment.

Age over 50 years was considered an independent risk factor. However, in the current work, 53\% [ 16 of 30 patients] were above 50 years. Van Tassel stated that $50 \%$ of patients are older than 50 years [Rule of 50] [33]. Additional risk factors include presence of comorbidities, like diabetes mellitus. Similar result were reached by Kwon et al. [18].

We found no correlation between CRP value at admission and the adverse outcome. The three cases with adverse outcome had CRP values at admission of 89,77 , and $70 \mathrm{mg} / \mathrm{L}$ [average $78.7 \mathrm{mg} / \mathrm{L}$ ]. Kwon et al. found that CRP at admission above $100 \mathrm{mg} / \mathrm{L}$ had bad outcome ${ }^{[18]}$.

The mortality rate was $3.3 \%$. The cause of death was cardiac arrest due to very bad general condition, highly elevated liver and kidney enzymes, bad blood gases. Casper et al. and Yoon et al. found one-year mortality rates were $4.62 \%, 2.2 \%$, and $6 \%$, respectively $[14,34$.

\section{Conclusion:}

Back pain is the first symptom in all patients. Contrasted $\mathrm{MRI}$ is the gold standard for diagnosis. ESR and CRP are very important in both diagnosis and follow up, TLC has a minimal role. Biopsies were positive in detecting the causative organism in half of patients. Chance should be given for conservative management before resorting to surgical intervention, and oral antimicrobial drug therapy is very effective in most patient. A minimum of 2 years follow up is recommended.

Financial and Non-financial Relationships and Activities of Interest

None to be declared

\section{REFERENCES}

1. Quesnele J, Dufton J, Stern P. Spinal infection: a case report. J Can Chiropr Assoc. 2012 Sep; 56[3]:209-15. [PMID: 22997471].

2. Yu SH, Kim DH, Kim HS, Nam KH, Choi BK, Han IH. Infectious Spondylodiscitis by Uncommon Pathogens: A Pitfall of Empirical Antibiotics. Korean J Spine. 2016 Sep; 13[3]:97-101. [DOI: 10.14245/kjs.2016.13.3.97].

3. Fong IW. Animals and Mechanisms of Disease Transmission. Emerging Zoonoses: Springer; 2017. p. 15-38.

4. Duarte RM, Vaccaro AR. Spinal infection: state of the art and management algorithm. Eur Spine J. 2013 Dec; 22 [12]:2787-99. [DOI: 10.1007/s00586-013-2850-1].

5. Gouliouris T, Aliyu SH, Brown NM. Spondylodiscitis: update on diagnosis and management. J Antimicrob Chemother. 2010 Nov;65 Suppl 3: iii11-24. [DOI: 10.1093/jac/dkq303].

6. Sheikh AF, Khosravi AD, Goodarzi H, Nashibi R, Teimouri A, Motamedfar A, Ranjbar R, Afzalzadeh S, Cyrus M, Hashemzadeh M. Pathogen Identification in Suspected Cases of Pyogenic Spondylodiscitis. Front Cell Infect Microbiol. 2017 Mar 9; 7:60. [DOI: 10.3389/fcimb.2017. 00060].

7. Berbari EF, Kanj SS, Kowalski TJ, Darouiche RO, Widmer AF, Schmitt SK, Hendershot EF, Holtom PD, Huddleston PM 3rd, 
Petermann GW, Osmon DR, Infectious Diseases Society of America. 2015 Infectious Diseases Society of America [IDSA] Clinical Practice Guidelines for the Diagnosis and Treatment of Native Vertebral Osteomyelitis in Adults. Clin Infect Dis. 2015 Sep 15; 61[6]:e26-46. [DOI: 10.1093/cid/civ482].

8. Miller JC, Palmer WE, Mansfield FL, Thrall JH, Lee SI. When is imaging helpful for patients with back pain? J Am Coll Radiol. 2006 Dec;3[12]:957-60. [DOI: 10.1016/j.jacr. 2006.03.001].

9. Klöckner $C$, Valencia R, Weber U. [Alignment of the sagittal profile after surgical therapy of nonspecific destructive spondylodiscitis: ventral or ventrodorsal method--a comparison of outcomes]. Orthopade. 2001 Dec; 30[12]:965-76. German. [DOI: 10.1007/ s001320170010]

10. Wille H, Dauchy FA, Desclaux A, Dutronc H, Vareil MO, Dubois V, et al. Efficacy of debridement, antibiotic therapy and implant retention within three months during postoperative instrumented spine infections. Infectious diseases. 2017; 49 [4]:261-7. [DOI: 10.1080/ 23744235. 2016.1255351]

11. Moon MS, Kim SS, Moon HL, Kim DH. Mycobacterium Tuberculosis in Spinal Tuberculosis. Asian Spine J. 2017 Feb;11[1]:138-149. [DOI: 10.4184/asj.2017.11.1.138].

12. McHenry MC, Easley KA, Locker GA. Vertebral osteomyelitis: longterm outcome for 253 patients from 7 Cleveland-area hospitals. Clin Infect Dis. 2002 May 15; 34[10]:1342-50. [DOI: 10.1086/340102].

13. Grammatico L, Baron S, Rusch E, Lepage B, Surer N, Desenclos JC, Besnier JM. Epidemiology of vertebral osteomyelitis in France: analysis of hospital-discharge data 2002-2003. Epidemiol Infect. 2008; 136[5]:653-60. [DOI: 10.1017/S0950268807008850]

14. Yoon SH, Chung SK, Kim KJ, Kim HJ, Jin YJ, Kim HB. Pyogenic vertebral osteomyelitis: identification of microorganism and laboratory markers used to predict clinical outcome. Eur Spine J. 2010 Apr; 19[4]:575-82. [DOI: 10.1007/s00586-009-1216-1]

15. Benzel EC. Postoperative Spinal Wound Infections and Postprocedural Diskitis. In: Benzel EC, editor. Spine Surgery: Techniques, Complication Avoidance, and Management. 2. Philadelphia, PA: Elsevier Health Sciences; 2012. p. 1891-7.

16. Carragee EJ. Pyogenic vertebral osteomyelitis. J Bone Joint Surg Am. 1997; 79[6]:874-80. [DOI: 10.2106/00004623-19970600000011].

17. Gentile L, Benazzo F, De Rosa F, Boriani S, Dallagiacoma G, Franceschetti G, Gaeta M, Cuzzocrea F. A systematic review: characteristics, complications and treatment of spondylodiscitis. Eur Rev Med Pharmacol Sci. 2019; 23[2 Suppl]:117-128. [DOI: 10.26355/eurrev_201904_17481].

18. Kwon JW, Hyun SJ, Han SH, Kim KJ, Jahng TA. Pyogenic Vertebral Osteomyelitis: Clinical Features, Diagnosis, and Treatment. Korean J Spine. 2017 Jun;14[2]:27-34. [DOI: 10.14245/kjs.2017.14.2.27].

19. Priest DH, Peacock JE Jr. Hematogenous vertebral osteomyelitis due to Staphylococcus aureus in the adult: clinical features and therapeutic outcomes. South Med J. 2005 Sep;98[9]:854-62. [DOI: 10.1097/01.smj.0000168666.98129.33]

20. Chelsom J, Solberg CO. Vertebral osteomyelitis at a Norwegian university hospital 1987-97: clinical features, laboratory findings and outcome. Scand J Infect Dis. 1998; 30[2]:147-51. [DOI: 10.1080/ 003655498750003537].
21. Stoffel M, Stüer C, Ringel F, Meyer B. Treatment of infections of the spine. Adv Tech Stand Neurosurg. 2011; [37]: 213-43. [DOI: 10.1007/978-3-7091-0673-0_7].

22. Zimmerli W. Clinical practice. Vertebral osteomyelitis. N Engl J Med. 2010 Mar 18; 362[11]:1022-9. [DOI: 10.1056/ NEJMcp0910753].

23. Marschall J, Bhavan KP, Olsen MA, Fraser VJ, Wright NM, Warren DK. The impact of prebiopsy antibiotics on pathogen recovery in hematogenous vertebral osteomyelitis. Clin Infect Dis. 2011 Apr 1; 52[7]:867-72. [DOI: 10.1093/cid/cir062].

24. Bettini N, Girardo M, Dema E, Cervellati S. Evaluation of conservative treatment of non specific spondylodiscitis. Eur Spine J. 2009 Jun; 18 Suppl 1[Suppl 1]:143-50. [DOI: 10.1007/s00586-009-0979-8]

25. Yang SC, Fu TS, Chen LH, Chen WJ, Tu YK. Identifying pathogens of spondylodiscitis: percutaneous endoscopy or CT-guided biopsy. Clin Orthop Relat Res. 2008 Dec; 466[12]:3086-92. [DOI: 10.1007/s11999-008-0441-y].

26. Talia AJ, Wong ML, Lau HC, Kaye AH. Safety of instrumentation and fusion at the time of surgical debridement for spinal infection. J Clin Neurosci. 2015 Jul;22[7]:1111-6. [DOI: 10.1016/j.jocn.2014. 12.028]

27. Livorsi DJ, Daver NG, Atmar RL, Shelburne SA, White AC Jr, Musher DM. Outcomes of treatment for hematogenous Staphylococcus aureus vertebral osteomyelitis in the MRSA ERA. J Infect. 2008; 57[2]:128-31. [DOI: 10.1016/j.jinf.2008.04.012].

28. Hong HS, Chang MC, Liu CL, Chen TH. Is aggressive surgery necessary for acute postoperative deep spinal wound infection? Spine. 2008; 33 [22]:2473-8. [DOI: 10.1097/BRS.0b013e 3181894ffo]

29. Euba G, Narváez JA, Nolla JM, Murillo O, Narváez J, GómezVaquero $\mathrm{C}$, Ariza J. Long-term clinical and radiological magnetic resonance imaging outcome of abscess-associated spontaneous pyogenic vertebral osteomyelitis under conservative management. Semin Arthritis Rheum. 2008 Aug;38[1]:28-40. [DOI: 10.1016/j. semarthrit.2007.08.007]

30. Rezai AR, Woo HH, Errico TJ, Cooper PR. Contemporary management of spinal osteomyelitis. Neurosurgery. 1999 May;44[5]:1018-25; discussion 1025-6. [DOI: 10.1097/00006123199905000-00047].

31. Yang SC, Fu TS, Chen HS, Kao YH, Yu SW, Tu YK. Minimally invasive endoscopic treatment for lumbar infectious spondylitis: a retrospective study in a tertiary referral center. BMC Musculoskelet Disord. 2014 Mar 27; 15:105. [DOI: 10.1186/1471-2474-15-105].

32. Pigrau C, Almirante B, Flores X, Falco V, Rodríguez D, Gasser I, Villanueva C, Pahissa A. Spontaneous pyogenic vertebral osteomyelitis and endocarditis: incidence, risk factors, and outcome. Am J Med. 2005 Nov;118[11]:1287. [DOI: 10.1016/ j.amjmed. 2005. 02.027].

33. Van Tassel P. Magnetic resonance imaging of spinal infections. Top Magn Reson Imaging. 1994 Winter;6[1]:69-81. [DOI: 10.1097/ 00002142-199400610-00010]

34. Casper DS, Zmistowski B, Hollern DA, Hilibrand AS, Vaccaro AR, Schroeder GD, et al. The effect of Postoperative Spinal Infections on Patient Mortality. Spine. 2017. [DOI: 10.1097/BRS. 00000000000 2277]. 

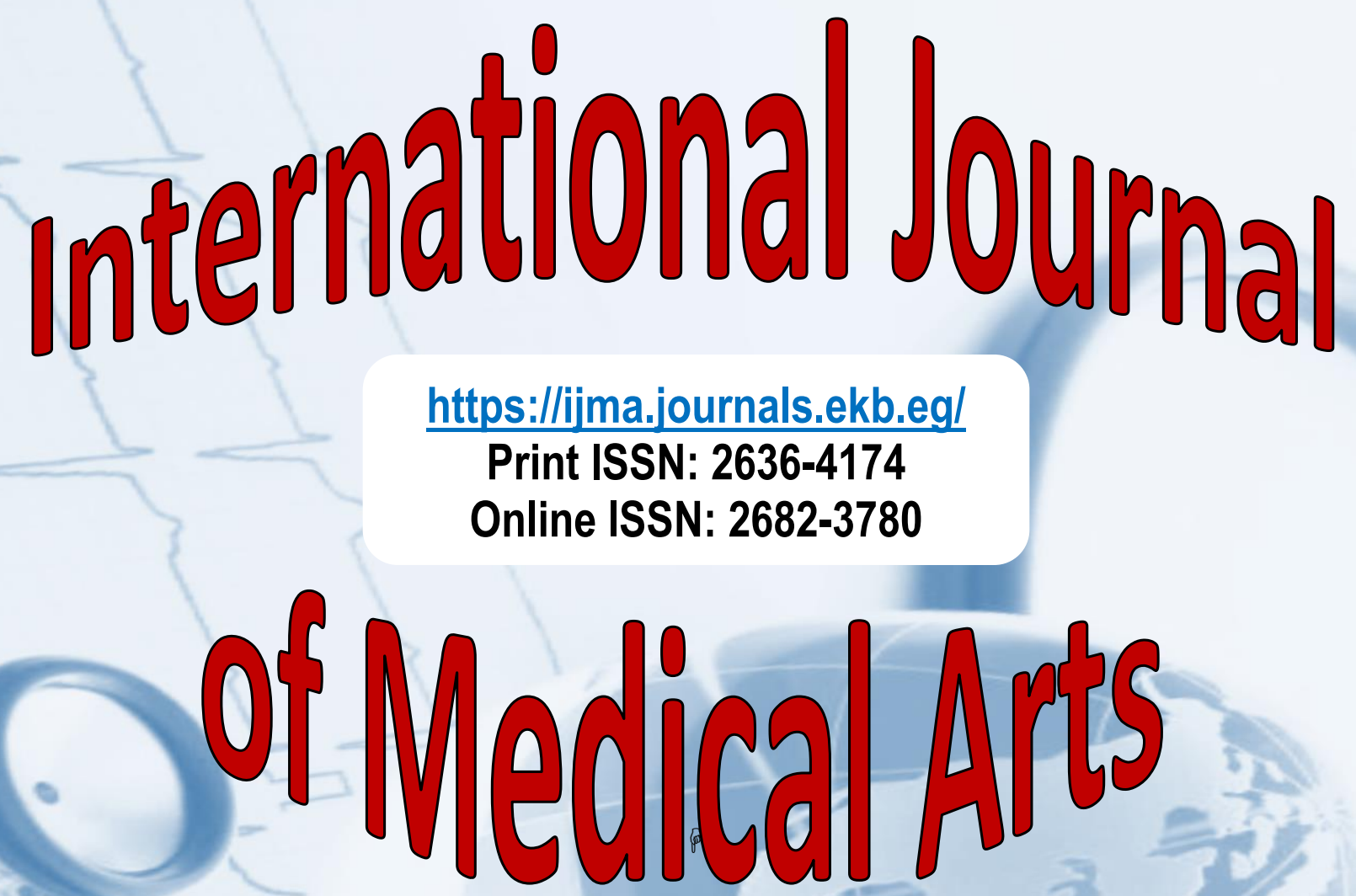